\title{
A Twin Study of Perthes Disease
}

David Metcalfe $^{\mathrm{a}, \mathrm{b}, \mathrm{c}}$ LLB MSc MRCS, Stephanie Van Dijck ${ }^{\mathrm{d}}$ FRACS, Nicolas Parsons ${ }^{\mathrm{c}}$ MSc PhD, Kaare Christensen ${ }^{\mathrm{e}} \mathrm{MD}$ PhD, Daniel C. Perry ${ }^{\mathrm{f}} \mathrm{PhD}$ FRCS(Orth)

\author{
Affiliations \\ ${ }^{a}$ Harvard Medical School, Boston, Massachusetts, USA; ${ }^{b}$ University of Oxford, Oxford, UK; ' University \\ of Warwick, Coventry, UK; ${ }^{\mathrm{d}}$ Middlemore Hospital, Auckland, New Zealand; 'University of Southern \\ Denmark, Odense, Denmark; fUniversity of Liverpool, Liverpool, UK
}

\section{Corresponding Author}

Dr. Daniel C. Perry, Institute of Translational Medicine, University of Liverpool, Liverpool, L12 2AP, UK. danperry@doctors.org.uk

\section{Short Title}

Twin Study of Perthes Disease

\section{Word Count}

\section{1,656}

\section{Financial Disclosure}

The authors have no financial relationships relevant to this article to disclose.

\section{Funding}

Data access was funded by the Perthes Association, U.K.

\section{Potential Conflicts of Interest}

The authors have no conflicts of interest relevant to this article to disclose

\section{Abbreviations}

Danish Twin Registry (DTR); dizygotic (DZ); International Classification of Disease (ICD); Legg-CalvéPerthes Disease (LCPD); monozygotic (MZ); standard deviation (SD); unknown zygosity (UZ).

\section{What's Known on This Subject}

Legg-Calvé-Perthes Disease (LCPD) is an idiopathic avascular necrosis of the femoral head. Its cause(s) are unknown but previous studies have implicated low birth weight and a possible genetic aetiology.

\section{What This Study Adds}

There is evidence of LCPD clustering within families but the absence of concordant monozygotic pairs in this study suggests that the cause(s) of LCPD may occur in utero or in the early childhood environment.

\section{Contributors' Statement}

Mr Metcalfe contributed to the study design, data analysis, data interpretation, and drafted the initial manuscript.

Dr Van Dijck and Professor Christensen contributed to the study design, data interpretation, and drafting of the manuscript.

Dr Parsons contributed to the study design, data analysis, and drafting of the manuscript.

Mr Perry conceived the original idea, conducted the primary data analysis, contributed to the manuscript, and is the study guarantor.

All authors approved the final manuscript version as submitted. 


\begin{abstract}
Background: Legg-Calvé-Perthes Disease (LCPD) is an idiopathic avascular necrosis of the femoral head. Its aetiology is poorly understood, although previous studies have implicated low birth weight and possible genetic determinants. The aim of this study was to identify potential birth weight and genetic associations with LCPD.

Methods: We extracted all twin pairs from the Danish Twin Registry (DTR) in which at least one individual had LCPD. The DTR captures every twin pair born alive in Denmark and those with LCPD were identified using health record linkage. Probandwise concordance was calculated to describe the likelihood that any given individual had LCPD if their co-twin was also diagnosed.

Results: There were 81 twin pairs; 10 monozygotic (MZ), 51 dizygotic (DZ), and 20 unclassified (UZ). There was no association between birth weight and being the affected co-twin. Four pairs (two dizygotic and two unclassified) were concordant for LCPD, which is greater than would be expected assuming no familial aggregation. There were no concordant $\mathrm{MZ}$ twin pairs. The overall probandwise concordance was 0.09 (95\% CI 0.01-0.18): 0.00 for the MZ, 0.08 (95\% CI 0.00-0.18) for the DZ, and 0.18 (95\% 0.00 0.40 ) for the UZ twin pairs.

Conclusions: This study found evidence of familial clustering in LCPD but did not demonstrate a genetic component. The absolute risk that a co-twin of an affected individual will develop LCPD is low, even in the case of $\mathrm{MZ}$ twin pairs.
\end{abstract}




\section{Introduction}

Legg-Calvé-Perthes Disease (LCPD) is an idiopathic avascular necrosis of the femoral head, with severe cases resulting in collapse of the femoral head and osteoarthritis in young adult life. It currently has an annual incidence of 6 cases per 100,000 children $^{1}$, which has been steadily in decline in recent years. The aetiology of LCPD is poorly understood. A number of studies have shown a strong association with socioeconomic deprivation in childhood..$^{2-4}$ Other proposed associations include small stature ${ }^{5}$, dietary deficiencies $^{6}$, passive smoking ${ }^{7,8}$, childhood hyperactivity ${ }^{9}$, white European ancestry, latitude distance from the equator ${ }^{10}$, and an inherited predisposition to abnormal clotting. ${ }^{11,12}$

In their early descriptions of LCPD, both Jacques Calvé and Georg Perthes described siblings with the disease. $^{13,14}$ There have since been a number of familial cases reported ${ }^{15}$, which raise the possibility of a major heritable component. Only two studies have used twins to investigate the aetiology of LCPD. ${ }^{5,16}$ These were both small series drawn from LCPD registries and reported a total of eleven pairs in which one twin had the disease. Although these studies could not demonstrate a genetic basis for LCPD, it was noted that the lowest birth weight twin was universally affected in the smaller series of five twin pairs. ${ }^{16}$

Twin studies are useful for delineating the importance of environmental and genetic factors. They can be used to study variation in environment (across pairs) and genetic constitution as "identical" (monozygotic, MZ) twins share almost 100\% of genes and "non-identical" (dizygotic, DZ) twins around $50 \% .{ }^{17}$ If $\mathrm{MZ}$ twins exhibit a greater concordance of LCPD than DZ twins, this suggests a genetic basis for the disease.

This study utilized a national cohort of LCPD twin pairs to explore the potential effects of heritability and birth weight on development of LCPD. We hypothesized that there would be a measurable heritable component to the aetiology of LCPD. 


\section{Patients and Methods}

A classical twin study was performed using the Danish Twin Registry (DTR). The Danish Data Protection Agency confirmed that ethical approval was not required for analysis of data from which patient identifiers were removed.

\section{Data source}

The DTR is the oldest national twin registry in the world with 85,000 twin pairs born in Denmark since 1870. ${ }^{18}$ Although different data sources have been used over the decades to identify twin pairs, manual searching of parish registers suggests that $80-90 \%$ of eligible twins born after 1931 were captured. However, the DTR has more recently identified twins using prospective administrative databases, i.e. the Medical Birth Register and Danish Civil Registration System, and is thought to have included every twin pair born alive in Denmark since $1^{\text {st }}$ April $1968 .{ }^{18}$ Zygosity within the DTR is determined by self-reported degree of similarity, which has been shown to assign the correct zygosity in $96 \%$ of cases when confirmed with genetic testing. ${ }^{19}$ Data within the DTR is collected using linkage to administrative datasets such as the Danish National Patient Register (all admissions to hospital since 1977 and outpatient visits since 1996), large-scale postal questionnaires (administered in 1966, 1994, 2002, and 2003), and regular interview surveys. ${ }^{20}$ Data was available until March 2014.

\section{Participants and variables}

All individuals with an International Classification of Disease (ICD) diagnosis code of LCPD captured within the national patient register during childhood ( $<16$ years old) were included. The ICD codes were ICD-8 722.11, and ICD-10 M91.1 and M91.2. We excluded those diagnostic codes for diseases that "mimic" LCPD to attenuate misclassification: multiple epiphyseal dysplasia (ICD-10 Q78.8), spondyloepiphyseal dysplasia (ICD-10 Q77.7), hypothyroidism diagnosed before 16 years old (ICD-8 244, ICD-10 E03.9), and hip dysplasia (ICD-8 755.6, ICD-10 Q65). We also excluded LCPD cases diagnosed before the age of two, as these were likely to represent either atypical disease or 
misclassification. In total, three twin pairs were excluded; one had a diagnosis of multiple epiphyseal dysplasia diagnosis and two received their LCPD diagnosis before the age of two years.

Data fields extracted were sex, zygosity and concordance for LCPD. Linkage to the Medical Birth Register enabled birth weight (to the nearest 100g) for each co-twin to be determined from the birth cohort 1979 onwards.

The total number of person years of exposure of 0-16 year olds within the twin cohort since data on inpatient admissions began to be routinely captured (Jan 1977) was 1,017,054 years.

\section{Statistical analysis}

Probandwise concordance describes the likelihood that the co-twin of an individual with LCPD would also have the disease. It is calculated using $2 \mathrm{X} /(2 \mathrm{X}+\mathrm{Y})$ where $\mathrm{X}$ represents the number of concordant pairs (both co-twins affected) and $\mathrm{Y}$ the discordant pairs. ${ }^{21}$

Chi squared $\left(\chi^{2}\right)$ tests were used for categorical variables and unpaired t-tests for normally distributed continuous variables. Poisson confidence intervals were used for estimates of disease incidence. All statistical analyses were performed using Stata 13.0 (College Station, TX, USA) and $p<0.05$ was adopted as the threshold for significance.

Outpatient diagnoses were not captured within the Danish National Register of Births until 1996 onwards. The data were therefore sub-analysed by a diagnostic date recorded "pre-1996", and "post-1996" to identify any systematic differences between these groups, particularly because less complex cases may be managed on a solely outpatient basis. 


\section{Results}

There were 81 twin pairs identified within the DTR, the earliest of which was born in 1966.74 males and 11 females were affected with a mean age of diagnosis at 6.3 years (95\% CI $5.6-7.0$ years). The incidence of LCPD disease was 8.4 cases (95\% CI 6.7 - 10.3) per 100,000 child years of exposure, equating to a cumulative incidence of 1.3 cases per thousand children. Ten pairs were MZ, $51 \mathrm{DZ}$ (25 opposite sex, 26 same sex), and 20 of unknown zygosity (UZ). There were only four concordant pairs: two each in the DZ same sex group and UZ groups. Based on this incidence, and assuming no familial aggregation, no concordant pairs were expected. Table 1 shows that the overall probandwise concordance was 0.09 (95\% CI $0.01-0.18)$ : 0.00 for the $\mathrm{MZ}, 0.08(0.00-0.18)$ for the $\mathrm{DZ}$, and $0.18(0.00-0.40)$ for the UZ group.

64 discordant pairs $(83.1 \%)$ had a birth weight recorded within the DTR. Birth weight was not different between those twins with LCPD and those without in any of the four groups (Table 2). Across the dataset of 64 discordant pairs with recorded birth weight, those with LCPD weighed $2.4 \mathrm{~kg}$ (SD $0.7 \mathrm{~kg}$ ) and those without $2.4 \mathrm{~kg}(\mathrm{SD} 0.7 \mathrm{~kg})(\mathrm{p}=0.999$, t-test). The affected twin was heaviest in $28(43.8 \%)$, lightest in 28 (43.8\%), and equal weight in $8(12.5 \%)$ cases $\left(p=0.632, \chi^{2}\right.$ test).

\section{Discussion}

This is the largest reported twin study to investigate the aetiology of LCPD but did not find any evidence of a strong heritable component or an association with birth weight. Although there were several episodes of concordance across the dataset of twins, none were found amongst the MZ pairs. Given that the cumulative incidence of LCPD across the whole twin registry was 1.3 cases per 1,000 children, the observation that four co-twins were affected amongst 81 twin-pairs suggests that LCPD does cluster within families. However, the absence of concordant $\mathrm{MZ}$ twin pairs suggests that such clustering is unlikely to have a strong genetic basis. As twins are typically raised together, it is possible that the origins of LCPD occur in utero or in the early childhood environment. 
A number of sibling cases have previously been described ${ }^{13-15}$, including reports of identical twins in which both children developed LCPD. ${ }^{22-25}$ However, these cases are likely to have been published because of the interesting observation of sibling concordance and so the literature is likely to reflect a selection bias. Studies that have reported high family concurrences often did not distinguish between LCPD and the many skeleletal dysplasias that affect the hip joint, e.g. multiple epiphyseal dysplasia. ${ }^{5}$ Two earlier studies that drew twins from LCPD registries were unable to support a genetic cause ${ }^{5} 16$ but included only eleven twin pairs (three MZ pairs). Our study of 81 twin pairs provides much stronger evidence of an environmental aetiology for LCPD.

In one of the two previous studies, Lappin et al noted that the affected individual was the lowest birth weight twin in all five cases..$^{5}$ This finding is consistent with evidence that children with LCPD are of relatively small stature ${ }^{26,27}$, have disproportionately reduced arterial caliber ${ }^{28}$, and may exhibit delayed skeletal maturation. ${ }^{29}$ However, there were no differences between the birth weights of affected and unaffected twins in our study. It is likely that the finding reported by Lappin et al arose by chance given the small number of patients in their series.

The strengths of this study are the relatively high number of twin pairs and use of a comprehensive population-based twin registry. This is important because both $\mathrm{MZ}$ and concordant twins are often overrepresented in disease registries. ${ }^{30,31}$ A further advantage of the DTR is that the diagnosis of LCPD was prospectively recorded as a part of routine clinical care due to linkage between the DTR and administrative datasets such as the Danish Patient Registry. Although internal validation of each LCPD diagnosis was not possible, the cumulative incidence was consistent with published literature and the appropriate age/sex distribution of cases offers external validity to suggest that disease coding was appropriate. 
The principal limitation of this study is the limited number of twin pairs available, particularly within the MZ group. Additionally zygosity was unavailable for two concordant twin pairs, which raises the theoretical possibility of there being two additional concordant MZ pairs. However, as the DTR is one of the largest twin registries in the world ${ }^{20}$, it is unlikely that a larger cohort of affected twin pairs could be identified without systematic registration of LCPD cases on an international scale.

\section{Conclusion}

We have reported the largest existing study of twin pairs affected by LCPD drawn from a comprehensive population registry. This data suggests that the absolute risk that a co-twin of an affected individual will develop LCPD is low, even in the case of MZ twin pairs. Although our study found evidence of familial clustering, it was unable to demonstrate a major genetic component.

\section{References}

1. Perry DC, Bruce CE, Pope D, Dangerfield P, Platt MJ, Hall AJ. Legg-Calve-Perthes disease in the UK: geographic and temporal trends in incidence reflecting differences in degree of deprivation in childhood. Arthritis Rheum. 2012;64(5):1673-1679.

2. Hall AJ, Margetts BM, Barker DJ, et al. Low blood manganese levels in Liverpool children with Perthes' disease. Paediatr Perinat Epidemiol. 1989;3(2):131-135.

3. Kealey WD, Moore AJ, Cook S, Cosgrove AP. Deprivation, urbanisation and Perthes' disease in Northern Ireland. J Bone Joint Surg Br. 2000;82(2):167-171.

4. Margetts BM, Perry CA, Taylor JF, Dangerfield PH. The incidence and distribution of LeggCalve-Perthes' disease in Liverpool, 1982-95. Arch Dis Child. 2001;84(4):351-354.

5. Wynne-Davies R, Gormley J. The aetiology of Perthes' disease. Genetic, epidemiological and growth factors in 310 Edinburgh and Glasgow patients. J Bone Joint Surg Br. 1978;60(1):6-14.

6. Hall AJ, Barker DJ, Dangerfield PH, Taylor JF. Perthes' disease of the hip in Liverpool. Br Med J (Clin Res Ed). 1983;287(6407):1757-1759.

7. Garcia Mata S, Ardanaz Aicua E, Hidalgo Ovejero A, Martinez Grande M. Legg-Calve-Perthes disease and passive smoking. J Pediatr Orthop. 2000;20(3):326-330.

8. Gordon JE, Schoenecker PL, Osland JD, Dobbs MB, Szymanski DA, Luhmann SJ. Smoking and socio-economic status in the etiology and severity of Legg-Calve-Perthes' disease. J Pediatr Orthop B. 2004;13(6):367-370.

9. Perry DC, Pope D, Bruce CE, Dangerfield P, Hall AJ, Platt MJ. Hyperactivity and the psychological burden of Perthes disease: a case-control study. J Pediatr Orthop. 2013;33(6):644649.

10. Perry DC, Machin DM, Pope D, et al. Racial and geographic factors in the incidence of LeggCalve-Perthes' disease: a systematic review. Am J Epidemiol. 2012;175(3):159-166.

11. Dilley A, Hooper WC, Austin H, et al. The beta fibrinogen gene G-455-A polymorphism is a risk factor for Legg-Perthes disease. J Thromb Haemost. 2003;1(11):2317-2321.

12. Balasa VV, Gruppo RA, Glueck CJ, et al. Legg-Calve-Perthes disease and thrombophilia. $J$ Bone Joint Surg Am. 2004;86-A(12):2642-2647. 
13. Calve J. On a particular form of pseudo-coxalgia associated with a characteristic deformity of the upper end of the femur. 1910. Clin Orthop Relat Res. 2006;451:14-16.

14. Perthes G. The classic: On juvenile arthritis deformans. 1910. Clin Orthop Relat Res. 2012;470(9):2349-2368.

15. Burlington H. Legg-Perthes disease in siblings; a report of two cases with simultaneous onset. $\mathrm{Pa}$ Med J. 1958;61(7):887-888.

16. Lappin K, Kealey D, Cosgrove A, Graham K. Does low birthweight predispose to Perthes' disease? Perthes' disease in twins. J Pediatr Orthop B. 2003;12(5):307-310.

17. Engell V, Damborg F, Andersen M, Kyvik KO, Thomsen K. Club foot: a twin study. J Bone Joint Surg Br. 2006;88(3):374-376.

18. Skytthe A, Kyvik K, Holm NV, Vaupel JW, Christensen K. The Danish Twin Registry: 127 birth cohorts of twins. Twin Res. 2002;5(5):352-357.

19. Christiansen L, Frederiksen H, Schousboe K, et al. Age- and sex-differences in the validity of questionnaire-based zygosity in twins. Twin Res. 2003;6(4):275-278.

20. Skytthe A, Kyvik KO, Holm NV, Christensen K. The Danish Twin Registry. Scand J Public Health. 2011;39(7 Suppl):75-78.

21. Lee MS, Lee SI, Yun S, Kang W. Concordance odds ratios and approximate rate ratios in longitudinal twin studies. Eur J Epidemiol. 2003;18(11):1047-1050.

22. Giannestras N. Legg-perthes disease in twins. J Bone Joint Surg Am. 1954;36-A(1):149-152.

23. Dunn AW. Coxa plana in monozygotic male twins. J Bone Joint Surg Am. 1960;42-A:178-183.

24. Inglis A. Genetic implications in coxa plana. J Bone Joint Surg Am. 1960;42-A:711-715.

25. Fisher RL. An epidemiological study of Legg-Perthes disease. J Bone Joint Surg Am. 1972;54(4):769-778.

26. Burwell RG, Dangerfield PH, Hall DJ, Vernon CL, Harrison MH. Perthes' disease. An anthropometric study revealing impaired and disproportionate growth. J Bone Joint Surg Br. 1978;60-B(4):461-477.

27. Hall AJ, Barker DJ, Dangerfield PH, Osmond C, Taylor JF. Small feet and Perthes' disease. A survey in Liverpool. J Bone Joint Surg Br. 1988;70(4):611-613.

28. Perry DC, Green DJ, Bruce CE, et al. Abnormalities of vascular structure and function in children with Perthes disease. Pediatrics. 2012;130(1):e126-131.

29. Harrison MH, Turner MH, Jacobs P. Skeletal immaturity in Perthes' disease. J Bone Joint Surg Br. 1976;58(1):37-40.

30. Harvald B, Hauge M. Hereditory factors elucidated by twin studies. In: Neel JV, Shaw MW, Schull WJ, eds. Genetics and the Epidemiology of Chronic Diseases. Washington DC: Department of Health, Education and Welfare; 1965.

31. Lykken DT, Tellegen A, DeRubeis R. Volunteer bias in twin research: the rule of two-thirds. Soc Biol. 1978;25(1):1-9. 


\begin{tabular}{|l|l|l|l|l|l|}
\hline \multicolumn{2}{|l|}{ Table 1: Twin pairs and probandwise concordance } \\
\hline & N pairs & Concordant & Discordant & Probandwise & $95 \% \mathrm{CI}^{\dagger}$ \\
& & & & concordance & \\
\hline MZ & 10 & 0 & 10 & 0.00 & - \\
\hline DZ & 51 & 2 & 49 & 0.08 & $0.00-0.18$ \\
\hline UZ & 20 & 2 & 18 & 0.18 & $0.00-0.40$ \\
\hline Overall & 81 & 4 & 77 & 0.09 & $0.01-0.18$ \\
\hline
\end{tabular}

$\dagger+/-2$ standard errors where $\mathrm{se}^{\wedge} 2=\left(\mathrm{rho}^{\wedge} 2\right)^{*}\left((1-\mathrm{rho})^{\wedge} 2\right)^{*}(1 / \mathrm{n} 11+1 / \mathrm{nd})$ or

rho*(1-rho)*(2-rho)/(2*n11+nd), expressions are equivalent. 


\begin{tabular}{|c|c|c|c|c|c|}
\hline \multirow[t]{2}{*}{ Group } & \multicolumn{3}{|c|}{ LCPD Affected Twin } & \multicolumn{2}{|l|}{ Mean birth weight } \\
\hline & Heaviest & Lightest & Same & Affected twins & Unaffected twins \\
\hline Monozygous $(\mathrm{n}=6)$ & 4 & 2 & 0 & $2.8 \mathrm{~kg}(\mathrm{SD} 0.3 \mathrm{~kg})$ & $2.6 \mathrm{~kg}(\mathrm{SD} 0.5 \mathrm{~kg})$ \\
\hline Dizygous same sex $(n=19)$ & 6 & 9 & 4 & $2.6 \mathrm{~kg}(\mathrm{SD} 0.5 \mathrm{~kg})$ & $2.6 \mathrm{~kg}(\mathrm{SD} 0.5 \mathrm{~kg})$ \\
\hline Dizygous opposite sex $(n=21)$ & 12 & 6 & 3 & 2.4kg (SD 0.7kg) & $2.4 \mathrm{~kg}(\mathrm{SD} 0.6 \mathrm{~kg})$ \\
\hline Unknown zygosity same sex $(n=18)$ & 6 & 11 & 1 & $2.1 \mathrm{~kg}(\mathrm{SD} 0.9 \mathrm{~kg})$ & $2.3 \mathrm{~kg}(\mathrm{SD} 0.9 \mathrm{~kg})$ \\
\hline Total $(n=64)$ & 28 & 28 & 8 & $2.4 \mathrm{~kg}(\mathrm{SD} 0.7 \mathrm{~kg})$ & $2.4 \mathrm{~kg}(\mathrm{SD} 0.7 \mathrm{~kg})$ \\
\hline
\end{tabular}

